\title{
CONTRIBUICQÃO PARA O ESTUDO DA CULTURA DO TUNGUE
}

\author{
Carivaldo Godoy Júnior \\ Assistente de Agricultura Especial \\ da Escola Superior de Agricultura "Luiz. de Queiroz"
}

INDICE

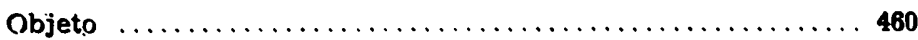

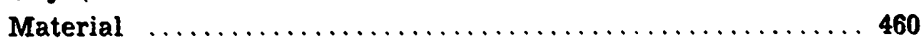

Resultados analíticos $\ldots \ldots \ldots \ldots \ldots \ldots \ldots \ldots \ldots \ldots \ldots \ldots$

Cálculo do exgotamento $\ldots \ldots \ldots \ldots \ldots \ldots \ldots \ldots \ldots \ldots \ldots .462$

Medidas para atenuar o exgotamento na cultura do Tungue 464

Torta de Tungue - Composição - Cálculo para adubação 465

Cálculo de adubação $\ldots \ldots \ldots \ldots \ldots \ldots \ldots \ldots \ldots \ldots \ldots \ldots 466$ 


\section{OBJETO}

O nosso trabalho visa o estudo do exgotamento produzido pela cultura do tungue e a possibilidade do emprêgo da torta como fonte reparadora.

\section{MATERIAL}

O material por nós utilizado fol fornecido pela Companhia Industrial e Agricola "Boyes", de Piracicaba, e constava de frutos maduros e secos, ao natural, provenientes da safra de 1946. Foram eles divididos em tres partes distintas, analisadas separadamente, uma vez determinadas as proporçరes porcentuais de : 1) amendoa, 2) tegumento, 3) pericarpo.

\section{METODOS DE ANALISE}

Foram os seguintes os métodos de análise por nós utilizados:

AZOTO TOTAL ......................... Kjeldah] ACIDO FOSFORICO (P205) .... Ataque pelos ácidos sulf. e nit. POTASSIO E SODIO (K20 e Na20) ...... Scholoesing-Wense. CALCIO (Ca. $\ldots \ldots \ldots \ldots \ldots \ldots \ldots \ldots \ldots$ Lemmerman. MAGNESIO (MgO) $\ldots \ldots \ldots \ldots \ldots \ldots \ldots \ldots \ldots \ldots$ Schmitz. OLEO ....................... etllico, no soxhlet

\section{RESULTADOS ANALTTICOS}

Os resultados analiticos que apresentamos representam a média de no mínimo tres análises, sendo suas porcentagens expressas em relaçáo à substancia natural. săo eles os seguintes:

\section{Quadro n. 1}

RELAÇAO PORCENTO ENTRE AMENDOA, TEGUMENTO E PERICARPO

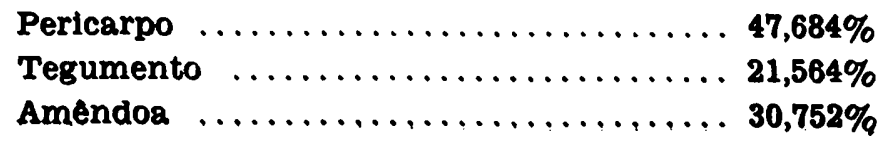


Quadro n. 2

COMPOSIÇAO CENTESIMAL DA AMENDOA

Humidade a $9^{\circ} \mathrm{C} \ldots \ldots \ldots \ldots \ldots \ldots \ldots \ldots \ldots, 4,113$

Oleo $\ldots \ldots \ldots \ldots \ldots \ldots \ldots \ldots \ldots \ldots \ldots \ldots \ldots 64,315$

$\mathbf{N}$ total $\ldots \ldots \ldots \ldots \ldots \ldots \ldots \ldots \ldots \ldots \ldots \ldots, \mathbf{2 , 5 0 3}$

P205 $\ldots \ldots \ldots \ldots \ldots \ldots \ldots \ldots \ldots \ldots \ldots \ldots \ldots, \quad \mathbf{0 , 8 8 7}$

$\mathbf{K 2 0} \ldots \ldots \ldots \ldots \ldots \ldots \ldots \ldots \ldots \ldots \ldots \ldots, \quad \mathbf{0 , 6 0 5}$

$\mathbf{N a 2 0} \ldots \ldots \ldots \ldots \ldots \ldots \ldots \ldots \ldots \ldots \ldots \ldots \ldots, \quad 0,190$

$\mathrm{CaO} \ldots \ldots \ldots \ldots \ldots \ldots \ldots \ldots \ldots \ldots \ldots \ldots \ldots, \quad \mathbf{0 , 0 9 2}$

Mg0 $\ldots \ldots \ldots \ldots \ldots \ldots \ldots \ldots \ldots \ldots \ldots, \quad 0, \mathbf{4 8 0}$

Cinza pura $\ldots \ldots \ldots \ldots \ldots \ldots \ldots \ldots \ldots \ldots, 2,353$

Quadro n. 3

COMPOSIÇAO CENTESIMAL DO TEGUMENTO

Humidade a $105^{\circ} \mathrm{C} \ldots \ldots \ldots \ldots \ldots \ldots \ldots \ldots, 10,623$

$\mathbf{N}$ total $\ldots \ldots \ldots \ldots \ldots \ldots \ldots \ldots \ldots \ldots \ldots \ldots, \quad 0,423$

P205 $\ldots \ldots \ldots \ldots \ldots \ldots \ldots \ldots \ldots \ldots \ldots \ldots, \quad 0,351$

$\mathbf{K 2 0} \ldots \ldots \ldots \ldots \ldots \ldots \ldots \ldots \ldots \ldots \ldots, \quad \mathbf{0 , 7 8 6}$

Na20 ............................. 0,166

Ca. $\ldots \ldots \ldots \ldots \ldots \ldots \ldots \ldots \ldots \ldots \ldots \ldots, \quad 1,024$

$\mathbf{M g 0} \ldots \ldots \ldots \ldots \ldots \ldots \ldots \ldots \ldots \ldots, \quad \mathbf{0 , 2 2 4}$

Cinza pura $\ldots \ldots \ldots \ldots \ldots \ldots \ldots \ldots \ldots, \quad 3,248$

Quadro n. 4

COMPOSIÇAO CENTESIMAL DO PERICARPO

Humidade a $105^{\circ} \mathrm{C} \ldots \ldots \ldots \ldots \ldots \ldots \ldots \ldots 13,038$

N total $\ldots \ldots \ldots \ldots \ldots \ldots \ldots \ldots \ldots \ldots \ldots \ldots, \quad 0,475$

P205 $\ldots \ldots \ldots \ldots \ldots \ldots \ldots \ldots \ldots \ldots \ldots \ldots, \quad 0,348$

$\mathbf{K 2 0} \ldots \ldots \ldots \ldots \ldots \ldots \ldots \ldots \ldots \ldots \ldots \ldots, \mathbf{3 , 5 7 1}$

Na20 $\ldots \ldots \ldots \ldots \ldots \ldots \ldots \ldots \ldots \ldots \ldots \ldots, \quad 0,321$

$\mathrm{CaO} \ldots \ldots \ldots \ldots \ldots \ldots \ldots \ldots \ldots \ldots \ldots \ldots, 0,428$

Mg0 ........................... 0,266

Cinza pura $\ldots \ldots \ldots \ldots \ldots \ldots \ldots \ldots \ldots \ldots, \mathbf{7 , 5 5 5}$

Destes dados resultam a seguinte composiçáo centesimal para as frutos inteiros: 
Quadro n. 5

COMPOSIÇAO CENTESIMAL DOS FRUTOS INTEIROS

\begin{tabular}{|c|c|c|c|c|}
\hline . & Amêndoa & Tegumento & Pericarpo & Fruto \\
\hline total. & 0,769 & 0,091 & 0,226 & 1,08 \\
\hline 05 & 0,272 & 0,075 & 0,165 & 51 \\
\hline 20 & 0,186 & 0,169 & 1,702 & 2,05 \\
\hline 9 & 0,058 & 0,035 & 0,153 & 0,24 \\
\hline & 0,028 & 0,220 & 0,204 & 0,45 \\
\hline$\ldots$ & 0,147 & 0,048 & 0,126 & 0,32 \\
\hline Cinsa pura & 0,723 & 0,700 & 3,602 & 5,02 \\
\hline
\end{tabular}

E para a semente :

Quadro n. 6

COMPOSIÇAO CENTESIMAL DA SEMENTE

Améndoa Tegumento Semente inteira

\begin{tabular}{|c|c|c|c|}
\hline $\mathrm{N}$ total & 1,469 & 0,173 & $\begin{array}{l}1,642 \\
0.662\end{array}$ \\
\hline P205 & 0,519 & 0,143 & 0,662 \\
\hline K20 & 0,355 & 0,322 & 0,677 \\
\hline $\mathrm{Na20}$ & 0,110 & 0,066 & 0,17 \\
\hline $\mathrm{CaO}$ & 0,053 & 0,425 & 0,47 \\
\hline Mg0 & 0,267 & 0,091 & 0,358 \\
\hline Cinza pura & 1,376 & 1,338 & 2,71 \\
\hline
\end{tabular}

\section{CALCULO DO EXGOTAMENTO}

Para este cálculo devemos saber antes qual é a produçăo média na cultura do tungue.

Armando Leal ("Tungue") fala em 2 a $3 \mathrm{kgs}$ por árvore, a.os quatro anos; em 15 a $35 \mathrm{kgs}$. a. 8-10 anos e finalmente, como média, cita 15 a 25 kgs., o que corresponderia a uma produção de 8.540 a $10.900 \mathrm{kgs}$. por alqueire, numa plantaçăo a $8 \mathrm{~m}$ por $8 \mathrm{~m}$, em quinconcio.

Para nossas cálculos vamas tomar como base uma produçăo de $20 \mathrm{kgs}$. por árvore, porque si ha árvores de produçбes excecionais de mals de $50 \mathrm{kgs}$. ("Tungue", A. Leal), tambẹm as há de produçరes bem inferiores àquele número, 
Vinte quilos de frutos correspondem, aproximadamente a :

9,537 kgs. de pericarpo,

$4,313 \mathrm{kgs}$. de tegumento,

6,150 kgs. de amendoa.

Traduzindo esses pesos em kgs. de elementos minerais, temos o quadro seguinte que representa o exgotamento anual de uma planta.

Quadro n. 1

EXGOTAMENTO ANUAL DE UMA PLANTA

\begin{tabular}{|c|c|c|c|c|c|}
\hline & $\mathbf{N}$ & P205 & $\mathrm{K} 20$ & $\mathrm{Ca2O}$ & Mg0 \\
\hline Pericarpo & 0,0453 & 0,0331 & 0,3405 & 0,0408 & 0,0253 \\
\hline Tegumento & 0,0182 & 0,0151 & 0,0339 & 0,0441 & 0,0096 \\
\hline Amêndoa & 0,1539 & 0,0545 & 0,0372 & 0,0056 & 0,0295 \\
\hline Totais & 0,2174 & 0,1027 & 0,4116 & 0,0905 & 0,0644 \\
\hline
\end{tabular}

O exgotamento por superfície val variar com os afastamentos adotados. Assim sendo, apresentamos o quadro abaixo, que mostix o exgotamento em kgs. por alqueire para as diferentes distaricias adotadas na cultura do tungue.

Quadro n. 8

EXGOTAMENTO EM KGS. POR ALQUEIRE

\begin{tabular}{|c|c|c|c|c|c|c|}
\hline Espaçamento & N. ${ }^{\circ}$ de & $\mathbf{N}$ & $\begin{array}{l}\mathbf{E} \times \mathbf{x} \\
\mathbf{P} 20\end{array}$ & a $\mathrm{m}$ & 0 & Mon \\
\hline inco & 569 & 123,700 & 58,436 & 234,200 & 51,494 & 36,643 \\
\hline$\times 8$ & 436 & 94,786 & 44,777 & 179,457 & 39,458 & 28,078 \\
\hline 7 (quadrad & 493 & 107,178 & 50,631 & 202,918 & 40,996 & 31,749 \\
\hline 88 & 378 & 82,177 & 38,820 & 155,584 & 34,209 & 24,343 \\
\hline $7(1)-3)$ & 432 & 93,916 & 44,366 & 177,811 & 39,096 & 27,820 \\
\hline
\end{tabular}

Façamos a comparaçáo do exgotamento no caso da cultura em quadrado de $8 \mathrm{~m} \times 8 \mathrm{~m}$ o que dá um número mínimo de plantas por superficie, com o ocasionado por uma colheita de 150 arrobas de algodáo, por alqueire, baseados em análises de R. Bolliger (Citaço de Gustavo R. D'Utra, em "Cultura do al. godoeiro"). 
Quadro n. 9

COMPARAÇAO ENTRE O EXGOTAMENTO DO TUNGUE E O ALGODAO

\begin{tabular}{|c|c|c|}
\hline & Tungue & Algodăo \\
\hline $\mathbf{N} t$ & 82,177 & 59,750 \\
\hline & 38,820 & 13,395 \\
\hline $\mathrm{K} 20$ & 155,584 & 17,535 \\
\hline $\mathrm{CaO}$ & 34,209 & 4,052 \\
\hline Mg0 & 24,343 & 9,315 \\
\hline
\end{tabular}

\section{CONCLUSOES}

1) Em relaçáo a todos os elementos, o tungue é mais exgotante que 0 algodáo (cultura considerada eminentemente exgotante). dåo.

2) 0 tungue exporta nove vezes mais potassio que o algo-

3) O tungue deve ser considerado como uma das culturas mais exgotantes do nosso Estado.

4) A questáo da adubação desta cultura deve, portanto, merecer especial atençáo, principalmente, pelo seu maior exgotamento em P205 e Ca0, e pelo fato de nossas terras já serem na sua maioria, originàriamente pobres dêsses elementos.

\section{MEDIDAS PARA ATENUAR O EXGOTAMENTO NA CULTURA DO TUNGUE}

Vejamos em primeiro lugar o que se passa com os frutos uma vez nas fábricas de óleo: primeiro, săo descascados mecanicamente, e as sementes, depois de quebradas, sao submetidas ao trabalho das prensas, daqui resultando o bleo de um lado e a torta de outro. Esta, no caso da extraça num "Expeller", sai continuamente sob a forma de finas placas, o que torna mais fácil sua moagem caso desejemos usá-la como adubo, uma vez que como alimento năo é preconizada em consequencia de ser venenosa.

Si fosse possivel o retorno das cascas e da torta às culturas, teriamos práticamente reduzido a zero o exgotamento; contudo, isto náo acontece na prática por dols motivos : primeiro. a questro de transporte, principalmente para a casca; segundo, esta e a torta representam ótimos combustiveis. 
A medida que sugerimos é a seguinte: importar da América do Norte descascadoras portáteis, que descaroçam os frutos de tungue na própria cultura, a medida que sáo recolhidos. As vantagens seriam tais que compensariam a aquisiçáo de tal maquina, porque :

a) As cascas ficariam na própria cultura como adubo, o que importaria numa reduçáo do exgotamento, mais ou menos, nas seguintes proporçбes: de $1 / 5$ para 0 azoto, de $1 / 3$ para 0 ácido fasfórico, de 5/6 para o potássio, de $1 / 2$ para o cálcio e de $2 / 5$ para o magnésio, como podemos avaliar no quadro abaixo.

\section{Quadro n. 10}

EXGOTAMENTO PRODUZIDO NUM ALQUEIRE DE CULTURA DE TUNGUE, EM QUADRADO DE 8X8, A RAZAO DE $10 \mathrm{KGS}$.

POR ARVORE, RETIRANDO-SE APENAS A SEMENTE

Quantidade de semente

$3.955 \mathrm{kgs}$.

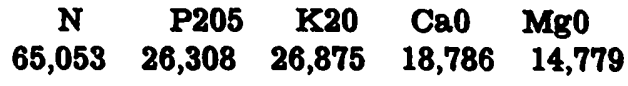

b) Barateariamos de, praticamente, $50 \%$ o transporte do produto, o que seria de grande alcance no presente momento em que há falta de transporte e os fretes săo bastante elevados.

c) Pelo fato acima e mais a dispensa de uma máquina e consequentemente de uma operaçăo na fabricaçăo, teriamos uma grande reduçăo no preço de custo do óleo.

Si a medida atraz preconizada for completada pela adubaça com a torta de tungue teriamos praticamente alcançado o máximo na questáo da restauraçăo do exgotamento.

TORTA DE TUNGUE. COMPOSIÇAO. CALCULO PARA ADUBAÇAO

A torta de tungue é, na prática, o residuo que se obtém da extraçăo do óleo das sementes, pois estas, em operaçáo prellminar, foram destituidas do pericarpo.

Submetendo à análise uma amostra de torta, da Companhia Industrial e Agrícola "Boyes" (Piracicaba), onde a extração do óleo, se faz num "Expeller", concluimos ser ela muito semelhante, na sua composiçăo, às demais existentes no mercado.

E a seguinte a sua composiçăo centesimal : 


\section{Quadro n. 11}

\section{COMPOSIÇAO CENTESIMAL DA TORTA DE TUNGUE}

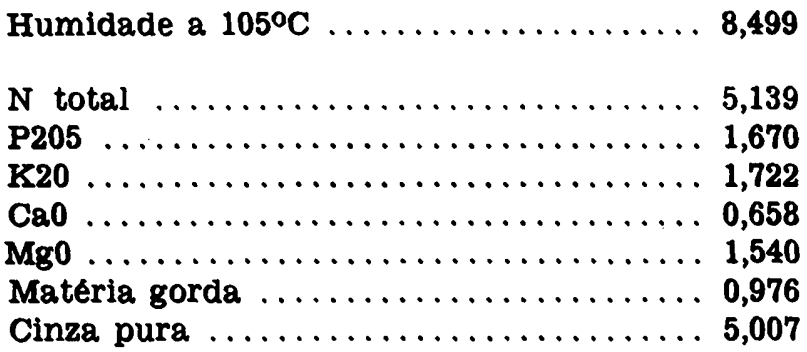

\section{CALCULO DE ADUBAÇÃO}

Vamas calcular a adubaçăo baseados no exgotamento de P205, elemento minimo em nossos solos, levando em conta que as cascas dos frutos não voltam para o campo.

Recorrendo ao quadro n. 7 (exgotamento por planta), vemos que para reparar a perda de 0,1027 kgs. de P205, devemos empregar 6,131 kgs. de torta por árvore, o que seria viável na prática, si náo ocorressem outros obstáculos, porque em uma produção de 20 quilos por pé, teriamos 10 de casca (50\%), 5 de óleo $(25 \%)$, e 5 de torta $(25 \%)$.

No caso de calcularmas na base do azoto, necessitamos de 4 quilos de torta, o que seria mais viável.

Fim relaçăo ao K20, o cálculo nos mostra ser impossível porque cada planta deveria receber 23 quilos de torta, quando apenas rende 5 quilos. Aqui se evidencia a importancia da devoluçăo da casca e, portanto, da vantagem da máquina descascadora portátil, americana. Com o uso desta, 4 quilos de torta reparariam o exgotamento de um planta.

Portanto, a adubaçăo do tungue, com sua própria torta, deve estar ao redor de, no mínimo, 5 quilos por planta, o que corresponde a 1.890 quilos, ou melhor, duas toneladas por alqueir?

NOTA : Para maiores detalhes sóbre a máquina descascadora referida ver o artigo de J. F. Reed e R. E. Jezek, na revista "A Fazenda", de Junho de 1946. ("A nova descascadora portátil para o fruto do tungue"). 